mirable institution over which you and Dr. Lowe so abiy and so skilfully preside.-Believe me, ever yours faithfully,

"Dr. John Smith."

- "Junx G. M. Burt.

$\because$

“ Saughtonhall; 20th November, 1865.

"Srr,-We shall esteem it a favour if you will insert the enclosed copy of letter in the next number of the 'Edinburgh Nedical Journal,' and will at the same time allow us to express to our professional brethren the gratitude we feel for their handsome testimonial. Were we merely to acknowledge their very liberal subscription of the sum of $\mathcal{\ell} 190$, we should do so with feelings of the utmost gratitude; but even this sum, large as it is, sinks into insignificance in comparison with the pleasure we must ever feel at this general and unequivocal testimony on the part of those whose good opinion we highly prize. We accept it as an acknowledgment of their sense of the injustice by which we were made the defendants in a prosecution, which was not only most uncalled for in the first instance, but which was allowed to sleep for twelve years before it was submitted to a public trial. At the trial we had the satisfaction of being supported by the Scottish Courts of Justice, and eventually by the unanimous decision of the House of Lords.

"Satisfactory as their decisions were, after a long and protracted trial, attended, we need hardly say, with great anxiety and expense, we have now to acknowledge a still higher satisfaction in this expression of the opinion of our professional brethren; and we beg most cordially to express the feelings of gratitude we must ever feel towards them for this unlooked for act of liberality and kindness. - We beg to remain, Sir, your very obedient servants,

"Joun Smith,

"WM. H. Lows."

Edinburgh Medical Journal, December, 1865.

\title{
Mr. John Blake, M.P., on the Desirability of an Uniform System of Treatment in Asylums for the Insane.
}

Corcenive as I do, that all public asylums have, since 1792, made steady progress in the direction of a more successful and enlightened principle of treatment, and feeling convinced that the moral treatment of the insane by kindness, occupation, and amusement, is now firmly established, I would venture to ask, why is the principle carried so much further in some institu. tions than in others? and, again, would it not be possible to lay down some general code of rules and regulations for the guidance of all public and private asylums in the United Kingdom, and thus afford to their inmates the fullest advantages, limited only by local circumstances, of liberty, occupation, and amusement? In visiting public asylums at home and abroad, $I$ have often been struck by the different principles which appear to guide the governing powers of almost neighbouring institutions. Thus, in England, the asylums of Leicester and York have absolutely no boundary wallsnothing beyond a quick-set hedge-while other English county asylums are protected by the old conventional high prison-like walls, and I may add that the official returns of these respective institutions show that the attempts at escape are less frequent in the unwalled than the walled asylums; and, what in a fiscal point of view, is of greater importance, the number of attendants 
required is less. At Gheel, in Belgium, the lunatics are confined by no boundary limit whatever - there is no wall, no hedge, no line of demarcation between the mentally afticted patient and the healthy colony in which he finds a refuge and a home. Indeed, in this admirable lunatic colony $I$ witnessed the insane and the sane working side by side at their various avocations, and with this almost incredibly encouraging result, that whereas Gheel receives only such cases as are deemed incurable, it actually cures 18 per cent. of its, I was about to say inmates-it would be more appropriate to term them guests. - The MForal Treatment of Insanity, and Suggestions for the Appointment of a Royal Commission to Report on the best System. By Joun A. Braxe, M.P.

\section{Publications Received, 1865.}

(Continued from the 'Journal of Mental Science,' October, 1865.)

- Clinical Lectures and Reports by the Medical and Surgical Staff of the London Hospital,' Vol. II, 1865. Churchill and Sons. See Pait III, Quarterly Report on the Progress of Psychological Mredicine.

'Time and Space: a Metaphysical Essay.' By Shadworth H. Hodgson. London : Longnians, Green, and Co, Paternoster Kow, pp. 588.

This Essay will be reviewed in our next number.

'Bathing: How to do it, When to do it, and Where to do it.' By Edgar Sheppard, M.D., Menter of the Royal College of Physicians, Fellow of the Royal College of Surgeons, Medical Superintendent of the Male Department of Colney Hatch Lunatic Asylum. London: Robert Hardwicke, 192, Piccadilly, 1865 (pamphlet.)

(Reprinted from the 'Journal of Mental Science,' July, 1865.)

'A Guide to the Treatment of Diseases of the Skin : with Suggestions for their prevention, for the use of the Student and General Practitioner.' By Thomas Hunt, F.R.C.S. Eighth edition. London, 1865.

- The Moral Treatment of Insanity, and Suggestions for the appointment of a Royal Commission to Keport on the best System.' By John Blake, M.P. Churchill and Sons, 1865 (pamphlet). See Part IV, Notes and Nevos.

'Cholera Prospects. Compiled from Personal Observation in the East, for the Information and Guidance of Individuals and Governments.' By Tilbury Fox, M.D. Lond. Robert Hardwicke, Piccadilly, 1865 (pamphlet).

'Diarrhœa and Cholera; their origin, proximate cause, and cure, through the agency of the Nervous System, by means of Ice.' By Johr Chapman, M.D. Trübner and Co. 1865, pp. 46 (pamphlet).

- On the Brain of a Bushwoman; and on the Brains of two Idiots of European Descent.' By John Marshall, F.R.S., Surgeon to University College Hospital.

This admirable essay, eprinted from the Philosophical Transactions, will be fully reviewed in our next number.

- On the Delirium of Acute Insanity during the decline of acute Diseases, especially the Delirium of Collapse.' By Hermann Weber, M.D., F.R.C.P., \&c.

$\Delta$ reprint of a valuable paper read brfore the MLedico-Chirurgical Society, and printed in the Transactions of the Sociely.

'Handbuch der Medicinischen-Statistık.' Von Dr. Fr. Oesterlen. Tübingen, 1865, pp. 968.

Dr. Oesterlen is already well known in Germany for his careful compilations, 